\title{
Health-related quality of life and scar satisfaction in a cohort of children operated on for sacrococcygeal teratoma
}

\author{
Mette Hambraeus ${ }^{1,2^{*}}$, Lars Hagander ${ }^{1,2}$, Einar Arnbjörnsson ${ }^{1}$, Anna Börjesson ${ }^{1}$ and Pernilla Stenström ${ }^{1,2}$
}

\begin{abstract}
Aim: The aims of this study were to evaluate health-related quality of life (HRQoL) in children with sacrococcygeal teratoma and to explore the effect of the scar on physical, emotional and behavioral aspects.

Methods: A cohort of children operated on for sacrococcygeal teratoma between 2000 and 2013 at Lund University Hospital, Sweden, and their parents were interviewed. HRQoL was evaluated with PedsQL, and scar satisfaction was estimated through Patient Observer Scar Assessment Score (POSA).

Results: All eligible children ( $n=17)$ were included (100\% response rate). Median age was 7.3 years (range 3.5-16.0). Mean total PedsQL score was 92.3 (range 72.0 to 99.0). Patients with comorbidity scored lower (87.5) than those without (95.0) ( $p<0.05)$. Pain during sitting down was reported by two $(20 \%)$ patients, and itching was reported by another two patients (20\%) aged $>8$ years. No children reported that they avoided situations due to the scar, and most ( $80 \%$ of children and $90 \%$ of parents) reported absent or only mild negative emotions when considering the scar.
\end{abstract}

Conclusion: Children with sacrococcygeal teratoma had a good overall HRQoL, but comorbidity reduced the outcome. A few children reported scar-related impact on physical, behavioral and emotional aspects.

Keywords: Sacrococcygeal teratoma, Health-related quality of life, Scar, Children

\section{Introduction}

Sacrococcygeal teratomas are rare congenital tumors with a birth prevalence of 1:10,000-1:40,000. The tumors are often diagnosed prenatally and may grow to enormous proportions with a risk of developing fetal hydrops and intrauterine demise [1-5]. Prenatal compression of surrounding pelvic structures and surgical trauma contribute to the well-described complication profile including urinary tract and bowel dysfunction [2, $6,7]$. In addition to functional considerations, children with sacrococcygeal teratomas often have a distinct scar

\footnotetext{
* Correspondence: mette.hambraeus@med.lu.se

${ }^{1}$ Department of Pediatric surgery, Skane University Hospital Lund, Lasarettgatan 48, 22241 Lund, Sweden

${ }^{2}$ Skane University Hospital, Department of Clinical Sciences Lund, Pediatric Surgery, Lund University, Lund, Sweden
}

and irregular buttock contour caused by the tumor's fragmentation of the gluteal musculature.

Health-related quality of life (HRQoL) is defined as a person's individual perception of a condition's impact on physical, mental and social aspects of life [8]. HRQoL has received increasing attention within pediatric specialties in recent decades, and it is a common concern to parents who are expecting a child with sacrococcygeal teratoma. Although transient problems with micturition and defecation may occur in otherwise healthy children, complications following sacrococcygeal teratoma often constitute a chronic condition with a potential to reduce HRQoL. Previous studies have found reduced HRQoL in children with urinary tract and bowel problems [9-11], which may imply that children born with sacrococcygeal

C The Author(s). 2020 Open Access This article is licensed under a Creative Commons Attribution 4.0 International License, which permits use, sharing, adaptation, distribution and reproduction in any medium or format, as long as you give appropriate credit to the original author(s) and the source, provide a link to the Creative Commons licence, and indicate if changes were made. The images or other third party material in this article are included in the article's Creative Commons licence, unless indicated otherwise in a credit line to the material. If material is not included in the article's Creative Commons licence and your intended use is not permitted by statutory regulation or exceeds the permitted use, you will need to obtain permission directly from the copyright holder. To view a copy of this licence, visit http://creativecommons.org/licenses/by/4.0/ The Creative Commons Public Domain Dedication waiver (http://creativecommons.org/publicdomain/zero/1.0/) applies to the data made available in this article, unless otherwise stated in a credit line to the data. 
teratoma are subjected to similar risks. A Dutch study evaluating adults born with sacrococcygeal teratoma showed no significant reduction in HRQoL [12], but no study has hitherto evaluated the impact on HRQoL during the course of childhood. Increased knowledge concerning aspects influencing HRQoL in patients born with sacrococcygeal teratoma would contribute to an evidence-based risk stratification of patients in early childhood, and this could potentially direct medical and psychological interventions towards improved long-term outcome. Therefore, this study aimed to evaluate HRQoL in children with sacrococcygeal teratoma, as well as to explore the effect of the postoperative scar on physical, emotional and behavioral aspects.

\section{Methods}

\section{Data collection}

We conducted a cross-sectional study of all surviving children operated on for sacrococcygeal teratoma during 2000-2013 at our tertiary center of pediatric surgery in Lund, Sweden. The interviews were carried out through 2016-2017 and the children were invited to an appointment at the children's hospital to convey this study. The patients and at least one parent were invited to the Children's Hospital to complete a questionnaire-based interview concerning HRQoL and scar satisfaction. A researcher not directly involved in the care of the patients conducted the interviews through asking the questions according to the questionnaires while clarifying uncertainties.

The cohort has previously been evaluated for prenatal growth pattern [4], and urinary tract/bowel symptoms at long-term follow up $[6,13]$. The results of the latter study were based upon data collected during the same interview setting and were integrated in the present study through comparing HRQoL in the children with and without reduced urinary/bowel function and comorbidites. No further socio-economic factors were evaluated.

\section{Instruments}

HRQoL was evaluated through the PedsQL 4.0 generic core scale, a validated questionnaire addressing children aged 2-18 years [14]. The questionnaire contains 23 items covering physical, emotional, social and school functioning. A psychosocial health summary score is based on an average of emotional, social and school functioning. The patients were asked to recall the past month and answer from 0 (never a problem) to 4 (almost always a problem). These scores were transformed into a 5-point Likert scale from $0=100 \%, 1=75 \%, 2=$ $50 \%, 3=25 \%, 4=0 \%$, where $100 \%$ corresponds to the highest possible HRQoL-score. Different versions of the questionnaire were based upon developmentally appropriate age groups, i.e. $2-4,5-7,8-12,13-18$ years.
Through the help of the interviewer, children aged 5 years and above answered the questions themselves, while a parent proxy questionnaire was used for children aged 2-4 years.

The parents' subjective opinion concerning scar appearance and symptoms was evaluated through the patient module of The Patient Observer Scar Assessment Score (POSAS) [15]. The POSAS was introduced in 2004 and aims to measure the quality of scar tissue through a patient and observer module. The questionnaire has previously been used as a proxy model to describe scars in children $[16,17]$. No observer evaluation of the physical appearance could be performed due to lack of ethical approval, and consequently only the patient module was used. The patient module of the POSAS evaluates experienced pain, pruritus, color, stiffness, thickness and regularity compared to normal skin. Each parameter is scored from 1 (as normal skin) to 10 (very unlike normal skin), yielding a total score ranging from 6 to 60, with 6 being the most advantageous outcome.

Children aged 8 years and above $(n=10)$ and available parents of all included children $(n=32)$ were asked independently to complete questions about behavioral and emotional aspects concerning the scar. The parents answered the questionnaires independently, while the interviewer helped the child when necessary. When only one parent could attend the visit at the children's hospital, a questionnaire filled in by the second parent (if applicable) was posted to the hospital after the interview.

\section{Statistical analysis}

PedsQL-scores in subgroups were described by median [range], and Mann-Whitney U-test was used to compare PedsQL-scores. Spearman correlation was used to analyze the relationship between PedsQL and POSA scores. Results were analyzed using IBM SPSS Statistics, version 24.0, Armonk, NY; IBM Corp.

\section{Results}

All eligible children $(n=17)$ were included in the study, yielding a response rate of $100 \%$. At the time of the questionnaire the children had a median age of 7.3 years (range 3.5-16.0), and the girl:boy ratio was 3.25:1. The functional results and tumor characteristics have been reported previously [6]: A total of $29 \%$ had neurogenic lesions of the bladder, $24 \%$ required medical treatment of constipation and $29 \%$ had problems with soiling. Two patients reported fecal incontinence - one girl reported occasional problems, and one girl was treated successfully with antegrade enemas through an appendicostomy. Four children had comorbidities: BeckwithWiedeman syndrome, familial hypercalciuria, attention deficit hyperactivity disorder (ADHD) and general 
anxiety. The remaining $76 \%$ of the cohort had no other diagnoses.

\section{Health-related quality of life}

The PedsQL 4.0 core instrument was completed for five children aged 2-4 years (by proxy), five children aged 57 years, five children aged 8-12 years and two children aged 13-18 years. HRQoL results are displayed in Table 1 . The median total PedsQL score was 94 ranging from 72 to 99 . The median psychosocial health summary score was 92, with high scores within all subcategories consisting of physical, social and school functioning. The proxy scores of young children aged 2-4 years did not differ significantly from those of older children completing self-report questionnaires.

Five children were diagnosed with neurogenic bladder/ bowel, of whom three children used self-catheterization to empty the bladder. These children did not report significantly altered HRQoL compared to children with normal urinary tract/bowel function (Table 2).

A comparison of children with and without comorbidities is presented in Table 3. The four children with comorbidities had significantly lower PedsQL overall score, physical score and school functioning score. The two children with ADHD and general anxiety disorder had lowest HRQoL, with total scores of 72.0 and 83.0 respectively.

\section{Implications of the scar}

Questionnaires regarding the postoperative scar were answered by patients aged 8 years and above $(n=10)$ and all available parents of the total cohort $(n=32)$. Two patients had scar revision performed - one at age 10 due to cosmetic considerations, the other at 1 year of age due to asymmetry and pain while sitting. There was no significant difference in how mothers and fathers experienced their child's scar. Mothers reported a median POSA score of 13.5 (6-36), and fathers 18.5 (6-47) $(p=$ 0.93). Figure 1 displays a plot of the correlation between PedsQL score and parents' POSA score. Spearman rank order test showed no significant correlation between the parameters $(p=0.37)$.

Table 1 Health related quality of life scores (PedsQL) in patients with sacrococcygeal teratoma

\begin{tabular}{lll}
\hline & Median & Range \\
\hline Total score & 94 & $72-99$ \\
Physical score & 97 & $78-100$ \\
Psychosocial health & 92 & $79-98$ \\
Emotional Functioning & 90 & $45-100$ \\
Social Functioning & 100 & $70-100$ \\
School Functioning & 95 & $60-100$ \\
\hline
\end{tabular}

A distribution of children's and parents' answers regarding physical symptoms, behavioral and emotional aspects is presented in Fig. 2. Physical symptoms related to the scar at the time of follow-up were uncommon in the cohort. Occasional pain during long periods of sitting down was reported by two $(20 \%)$ patients, and itching was a problem for two $(20 \%)$ other patients. The majority of children and parents thought of the scar only rarely or not at all. Frequent thoughts concerning the scar were reported by one child and by $18 \%$ of the parents. One mother described having negative thoughts of the scar several times every day, while one father described feelings of gratitude when seeing or thinking of the scar, since this reminded him of how lucky the family had been.

Both child and proxy reports showed that $70 \%$ of the children never and 30\% rarely avoided situations due to the scar. No children experienced consistently evading behavior, neither self or proxy-reported. Two children avoided wearing certain types of tight clothes due to the scar, but only on rare occasions. The vast majority of children and parents reported absent or mild negative emotions when thinking of the scar, while $20 \%$ of the children and $10 \%$ of parents were moderately sad when considering the scar. Many children attributed the low level of distress to the discrete location of the scar, being concealed in most situations.

\section{Discussion}

This study showed that children born with sacrococcygeal teratoma had a very good overall HRQoL. Physical symptoms and behavioral/emotional consequences were uncommon in the cohort, and we found no correlation between parents' assessment of the scar and the HRQoL of the child.

The results showing a good overall HRQoL in this patient group correlate well with the study by Shalaby et al. presenting low levels of appearance-related distress in adults with sacrococcygeal teratoma [18], and a study by Kremer et al. reporting normal HRQoL among adults operated on for sacrococcygeal teratoma during childhood [12]. The HRQoL of healthy Swedish children has not been analyzed using the PedsQL 4.0 generic core scale. The original validation study of the PedsQL questionnaire analyzed healthy American children with a mean age of 9.3 years, and found a mean total PedsQL score of 83.0, a physical score of 84.4 and a psychosocial health score of 82.4 [14]. These PedsQL-scores seem to be inferior to those of the children with sacrococcygeal teratoma included in this study (Table 1), although no statistical comparison can be made due to the small number of children analyzed in the present study.

Children with urinary tract/bowel dysfunction had HRQoL scores equivalent to those of sacrococcygeal 
Table 2 Health related quality of life scores (PedsQL) in sacrococcygeal teratoma patients with neurogenic bladder and/or neurogenic bowel function compared to patients with normal bladder and bowel function

\begin{tabular}{|c|c|c|c|c|c|}
\hline & \multicolumn{2}{|c|}{ Neurogenic bladder/bowel function $(\boldsymbol{N}=5)$} & \multicolumn{3}{|c|}{ Normal bladder/bowel function $(\boldsymbol{N}=12)$} \\
\hline & Median & Range & Median & Range & $P$ \\
\hline Total score & 93.0 & $72-97$ & 95.0 & $83-99$ & $0.19^{a}$ \\
\hline Physical score & 94.0 & $78-100$ & 97.0 & $91-100$ & $0.83^{a}$ \\
\hline Psychosocial health & 94.0 & $68-97$ & 92.0 & $78-98$ & $0.56^{a}$ \\
\hline Emotional functioning & 90.0 & $75-100$ & 90.0 & $45-100$ & $0.75^{a}$ \\
\hline Social functioning & 100.0 & $70-100$ & 100.0 & $90-100$ & $0.71^{a}$ \\
\hline School functioning & 90.0 & $60-95$ & 100.0 & $75-100$ & $0.07^{a}$ \\
\hline
\end{tabular}

${ }^{a}$ Mann-Whitney U-test

teratoma patients without functional problems. This is somewhat surprising considering several authors reporting lowered self-esteem among children with urinary incontinence [10] and constipation [11]. Bongers et al. found a high impact on emotional functioning in children with constipation and fecal incontinence, while social function was less affected [9]. The two children with fecal incontinence in our study were only 4 and 5 years old at the time of the study; according to a study by Grano et al. increasing impact on HRQoL may occur with age [19].

Children with comorbidities scored significantly lower on physical and school functioning, especially two children with ADHD and general anxiety disorder. This indicates that HRQoL among children with sacrococcygeal teratoma is more contingent upon comorbidities than the teratoma per se. Several previous studies have reported reduced HRQoL in children with ADHD [20], but to the authors' best knowledge, no studies have described increased prevalence of ADHD among children operated on for sacrococcygeal teratoma. However, a possible causative link between the diagnoses could be the increased risk of very premature birth associated with large sacrococcygeal teratoma [21, 22], which has been correlated to higher levels of ADHD and autism spectrum diagnoses [23].
In general, generic HRQoL instruments have a lower sensitivity to detect reduced health-related quality of life within a specific diagnosis, and especially in congenital diseases, when compared to disease-specific instruments [8]. No disease-specific HRQoL instrument exists for sacrococcygeal teratoma, and the generic nature of the questionnaire may partly explain the good self-reported HRQoL compared with healthy children. Generic psychosocial scores approaching normal values have been found by some authors in other chronic childhood illnesses, i.e. cystic fibrosis [24] and diabetes [25]. Coping strategies in children with chronic diagnoses are well studied [26], and may explain differences in HRQoL regardless of comparable symptoms.

\section{Physical, emotional and behavioral aspects of the scar}

The parents' overall assessment of the scar was located in the lower third of the POSA scale, expressing a good overall satisfaction with the cosmetic outcome. The vast majority of children and parents thought very little of the scar, and comments during the interviews indicated that children and parents were grateful for the discrete location of the scar. This information is important to convey in the prenatal and early postoperative phase, when parents often worry about the cosmetic

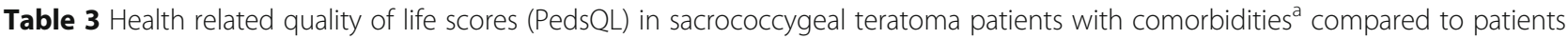
without comorbidities

\begin{tabular}{|c|c|c|c|c|c|}
\hline & \multicolumn{2}{|c|}{ Comorbidities $(\boldsymbol{N}=4)$} & \multicolumn{3}{|c|}{ No comorbidities $(\boldsymbol{N}=13)$} \\
\hline & Median & Range & Median & Range & $P$ \\
\hline Total score & 87.5 & $72-94$ & 95.0 & $86-99$ & $<0.05^{b}$ \\
\hline Physical score & 87.5 & $78-94$ & 97.0 & $91-100$ & $<0.01^{b}$ \\
\hline Psychosocial health & 86.0 & $68-96$ & 92.0 & $79-98$ & $0.35^{b}$ \\
\hline Emotional functioning & 82.5 & $65-100$ & 90.0 & $45-100$ & $0.70^{b}$ \\
\hline Social functioning & 95.0 & $70-100$ & 100.0 & $90-100$ & $0.20^{b}$ \\
\hline School functioning & 81.5 & $60-92$ & 95.0 & $75-100$ & $<0.05^{b}$ \\
\hline
\end{tabular}

${ }^{a}$ Beckwith-Wiedeman, familial hypercalciuria, ADHD, general anxiety disorder

${ }^{\mathrm{b}}$ Mann-Whitney U-test 


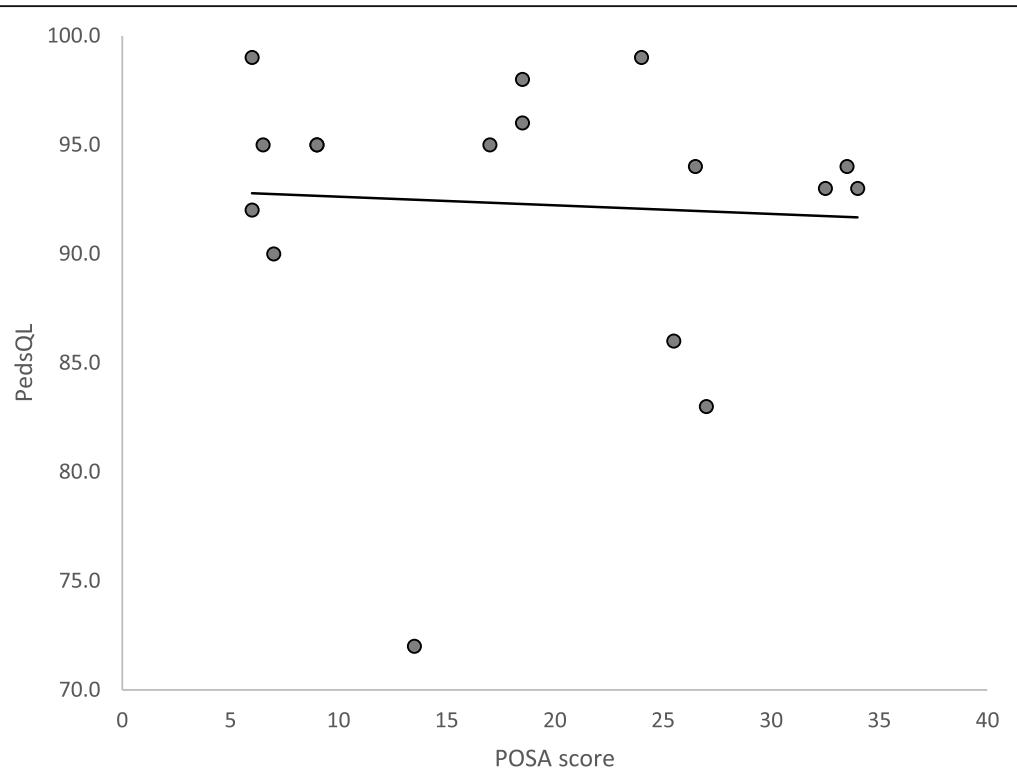

Fig. 1 Correlation between the children's PedsQL-score (0-100) and parents' average POSA score (6-60, with high score indicating poor outcome). $N=17$. Spearman correlation: $p=0.37$

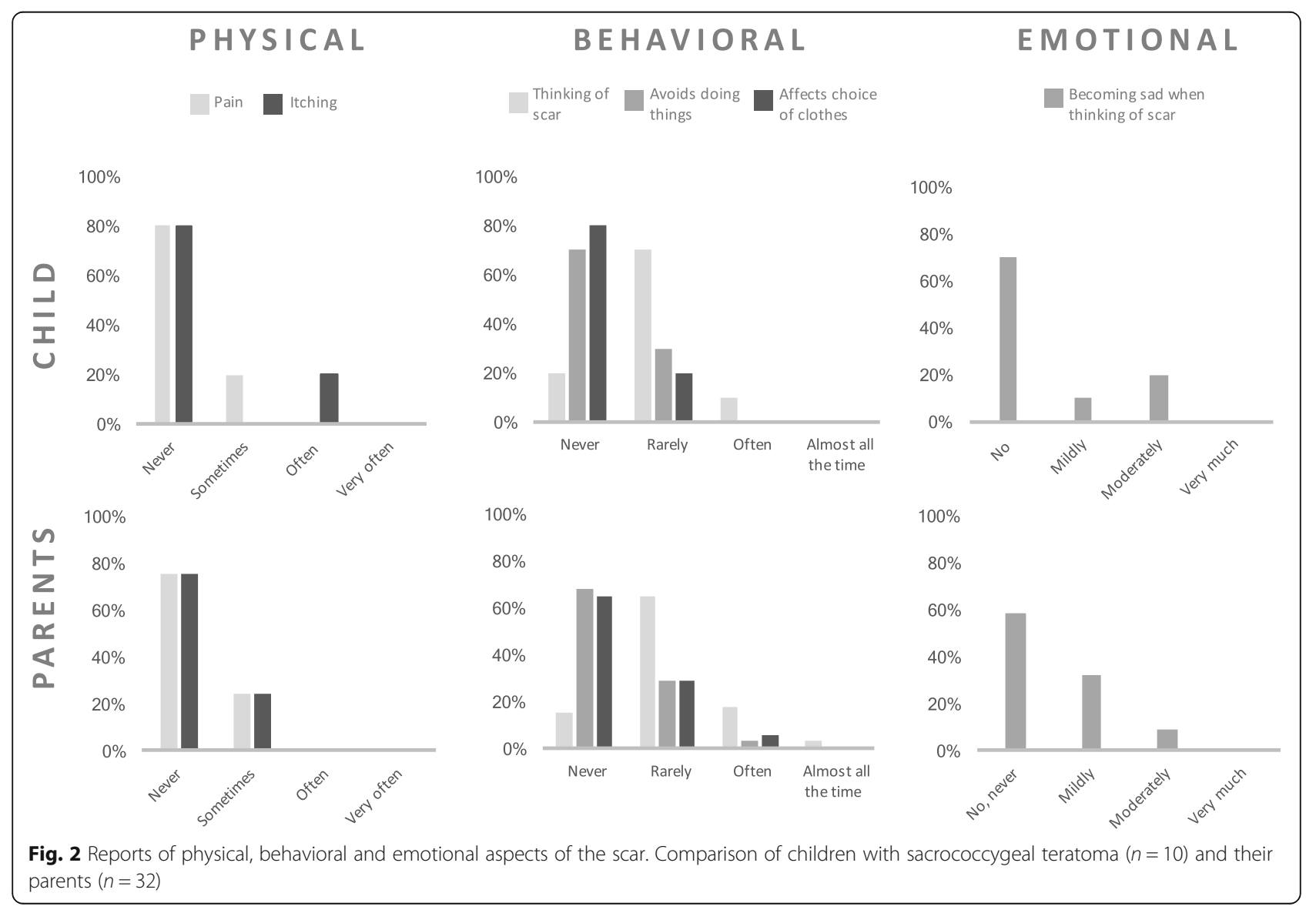


appearance of the scar, and what this may entail for the future of the child.

A Dutch long-term follow-up study by Derikx et al. [2] showed a high frequency of dissatisfaction with the scar following sacrococcygeal teratoma resection, with 40.3\% reporting a cosmetically unacceptable result. Dissatisfaction was found to be correlated to large tumor size and early diagnosis of the teratoma. The included patients were somewhat older than our cohort, up to 22 years of age, and it is possible that dissatisfaction increases in adolescence and early adulthood. In addition, cultural differences may partly explain the heterogeneity in outcome concerning appearance-related satisfaction and HRQoL.

\section{Limitations}

Due to the rarity of the disorder the number of included patients in the cohort is small, which limits conclusions being drawn from the study. We used a generic HRQoL instrument, which enables comparison with healthy children and other diagnostic categories. However, generic instruments reduce sensitivity, and construction of a validated questionnaire for sacrococcygeal teratoma, including bladder, bowel and scar aspects, could possibly further elucidate problems concerning HRQoL. Future studies should evaluate whether children with comorbidities, especially neuropsychiatric disorders, have a reduced capability to cope with functional complications following sacrococcygeal teratoma. These children could then be identified early in order to increase self-efficacy, reduce stress and endorse adaptive, problem-solving coping strategies. Further, our study group is young and problems concerning both cosmetics and reduced HRQoL due to micturition/bowel issues may emerge during the course of adolescence and early adulthood. In addition, the time prolapsed since surgery varies in the study group which could possibly impact the outcome. Longitudinal studies following the children until the third decade of life could potentially help shed light on the dynamics of HRQoL in this patient group.

\section{Conclusion}

In conclusion, according to generic quantitative measurements, children with sacrococcygeal teratoma had a good overall HRQoL during childhood. Children with a comorbidity had reduced outcome regarding HRQoL. Few children had physical symptoms concerning their scar, and scar-related impact on behavior or emotions was generally very low. The present findings are useful in the prenatal and postoperative setting, when the child's future and general HRQoL is of paramount concern to the parents.

\section{Abbreviations}

HRQoL: Health-related quality of life; POSAS: Patient observer scar assessment score; ADHD: Attention deficit hyperactivity disorder

\section{Acknowledgements}

Not applicable.

\section{Authors' contributions}

All authors contributed to the work and accepted the final version. $\mathrm{MH}$ collected, analyzed and interpreted data, and wrote the manuscript. LH and EA supervised in data analysis and interpretation, and contributed with preparing the finalized manuscript. AB and PS designed the study, contributed with disease-specific knowledge and data collection, and revised the manuscript. Only the listed authors contributed to the study.

\section{Funding}

Governmental and university funding. Open access funding provided by Lund University.

\section{Availability of data and materials}

The datasets used and/or analyzed during the current study are available from the corresponding author on reasonable request.

\section{Ethics approval and consent to participate}

The study was approved by the regional Research Ethics Committee (Lund, registration number 2016/289), and written consent from both parents was obtained for all patients.

Consent for publication

All participants consented to publication of the study.

\section{Competing interests}

The authors declare that they have no competing interests.

Received: 26 February 2019 Accepted: 2 April 2020

Published online: 17 April 2020

\section{References}

1. Altman RP, Randolph JG, Lilly JR. Sacrococcygeal teratoma: American Academy of Pediatrics surgical section Survey-1973. J Pediatr Surg. 1974;9(3): 389-98.

2. Derikx JP, De Backer A, van de Schoot L, Aronson DC, de Langen ZJ, van den Hoonaard TL, et al. Long-term functional sequelae of sacrococcygeal teratoma: a national study in the Netherlands. J Pediatr Surg. 2007;42(6): 1122-6.

3. Forrester MB, Merz RD. Descriptive epidemiology of teratoma in infants, Hawaii, 1986-2001. Paediatr Perinat Epidemiol. 2006;20(1):54-8.

4. Hambraeus M, Arnbjornsson E, Borjesson A, Salvesen K, Hagander L. Sacrococcygeal teratoma: a population-based study of incidence and prenatal prognostic factors. J Pediatr Surg. 2016;51(3):481-5.

5. Pauniaho SL, Tatti O, Lahdenne P, Lindahl H, Pakarinen M, Rintala R, et al. Tumor markers AFP, CA 125, and CA 19-9 in the long-term follow-up of sacrococcygeal teratomas in infancy and childhood. Tumour Biol. 2010;31(4): 261-5.

6. Hambraeus M, Hagander L, Stenstrom P, Arnbjornsson E, Borjesson A. Longterm outcome of sacrococcygeal teratoma: a controlled cohort study of urinary tract and bowel dysfunction and predictors of poor outcome. J Pediatr. 2018;198:131-6.

7. Kremer ME, Derikx JP, van Baren R, Heij HA, Wijnen MH, Wijnen RM, et al. Patient-reported defecation and micturition problems among adults treated for Sacrococcygeal Teratoma during childhood--the need for new surveillance strategies. Pediatr Blood Cancer. 2016;63(4):690-4.

8. Palermo TM, Long AC, Lewandowski AS, Drotar D, Quittner AL, Walker LS. Evidence-based assessment of health-related quality of life and functional impairment in pediatric psychology. J Pediatr Psychol. 2008;33(9):983-96 discussion 97-8.

9. Bongers ME, van Dijk M, Benninga MA, Grootenhuis MA. Health related quality of life in children with constipation-associated fecal incontinence. J Pediatr. 2009;154(5):749-53.

10. Deshpande AV, Craig JC, Smith GH, Caldwell PH. Factors influencing quality of life in children with urinary incontinence. J Urol. 2011;186(3):1048-52. 
11. Rajindrajith S, Devanarayana NM, Crispus Perera BJ, Benninga MA. Childhood constipation as an emerging public health problem. World J Gastroenterol. 2016;22(30):6864-75.

12. Kremer ME, Dirix M, Koeneman MM, van Baren R, Heij HA, Wijnen MH, et al. Quality of life in adulthood after resection of a sacrococcygeal teratoma in childhood: a Dutch multicentre study. Arch Dis Child Fetal Neonatal Ed. 2015;100(3):F229-32.

13. Hambraeus M, Al-Mashhadi A, Wester T, Svensson PJ, Stenstrom P, Lilja HE. Functional outcome and health-related quality of life in patients with sacrococcygeal teratoma - a Swedish multicenter study. J Pediatr Surg. 2019:54(8):1638-43.

14. Varni JW, Seid M, Kurtin PS. PedsQL 4.0: reliability and validity of the pediatric quality of life inventory version 4.0 generic core scales in healthy and patient populations. Med Care. 2001;39(8):800-12.

15. Draaijers $\sqcup$, Tempelman FR, Botman YA, Tuinebreijer WE, Middelkoop E, Kreis RW, et al. The patient and observer scar assessment scale: a reliable and feasible tool for scar evaluation. Plast Reconstr Surg. 2004;113(7):1960-5 discussion 6-7.

16. Gee Kee E, Kimble RM, Cuttle L, Stockton K. Comparison of three different dressings for partial thickness burns in children: study protocol for a randomised controlled trial. Trials. 2013;14:403.

17. Ortavist L, Almstrom M, Ojmyr-Joelsson M, Wigander $H$, Wahrner A, Wester T. Cosmetic and functional outcome after stoma site skin closure in children. Pediatr Surg Int. 2011;27(10):1123-6.

18. Shalaby MS, Dorris L, Carachi R. The long-term psychosocial outcomes following excision of sacrococcygeal teratoma: a national study. Arch Dis Child Fetal Neonatal Ed. 2014;99(2):F149-52.

19. Grano C, Bucci S, Aminoff D, Lucidi F, Violani C. Transition from childhood to adolescence: quality of life changes 6 years later in patients born with anorectal malformations. Pediatr Surg Int. 2015;31(8):735-40.

20. Danckaerts M, Sonuga-Barke EJ, Banaschewski T, Buitelaar J, Dopfner M, Hollis C, et al. The quality of life of children with attention deficit/ hyperactivity disorder: a systematic review. Eur Child Adolesc Psychiatry, 2010;19(2):83-105.

21. Gebb JS, Khalek N, Qamar H, Johnson MP, Oliver ER, Coleman BG, et al. High tumor volume to fetal weight ratio is associated with worse fetal outcomes and increased maternal risk in fetuses with sacrococcygeal Teratoma. Fetal Diagn Ther. 2019;45:94-101.

22. Usui N, Kitano Y, Sago H, Kanamori Y, Yoneda A, Nakamura T, et al. Outcomes of prenatally diagnosed sacrococcygeal teratomas: the results of a Japanese nationwide survey. J Pediatr Surg. 2012;47(3):441-7.

23. Broring T, Oostrom K, van Dijk-Lokkart EM, Lafeber HN, Brugman A, Oosterlaan J. Attention deficit hyperactivity disorder and autism spectrum disorder symptoms in school-age children born very preterm. Res Dev Disabil. 2018;74:103-12.

24. de Jong W, Kaptein AA, van der Schans CP, Mannes GP, van Aalderen WM, Grevink RG, et al. Quality of life in patients with cystic fibrosis. Pediatr Pulmonol. 1997:23(2):95-100.

25. Nieuwesteeg A, Pouwer F, van der Kamp R, van Bakel H, Aanstoot HJ, Hartman E. Quality of life of children with type 1 diabetes: a systematic review. Curr Diabetes Rev. 2012;8(6):434-43.

26. Compas BE, Jaser SS, Dunn MJ, Rodriguez EM. Coping with chronic illness in childhood and adolescence. Annu Rev Clin Psychol. 2012;8:455-80.

\section{Publisher's Note}

Springer Nature remains neutral with regard to jurisdictional claims in published maps and institutional affiliations.

Ready to submit your research? Choose BMC and benefit from:
- fast, convenient online submission
- thorough peer review by experienced researchers in your field
- rapid publication on acceptance
- support for research data, including large and complex data types
- gold Open Access which fosters wider collaboration and increased citations
- maximum visibility for your research: over 100M website views per year
At BMC, research is always in progress.
Learn more biomedcentral.com/submissions

